\title{
Variability in Antiplatelet Drugs' Response in Indian Patients Undergoing Percutaneous Coronary Intervention and Outcome Modification by Tailored Antiplatelet Therapy
}

\author{
R Madhavi, D Rajasekhar*, V Vanajakshamma, G Obul Reddy, C Kapil and G Sowjenya \\ Department of Cardiology, Sri Venkateswara Institute of Medical Sciences, India
}

Submission: January 22, 2018; Published: February 19, 2018

*Corresponding author: Durgaprasad Rajasekhar, Department of Cardiology, Sri Venkateswara Institute of Medical Sciences (SVIMS), Tirupati, Andhra Pradesh-517507, India, Tel: +91-8772288133/+91-9849221650; Email: drdrsekhar@gmail.com

\begin{abstract}
Background: Double or triple antiplatelet therapy is a guideline mandated therapy for patients who undergo Percutaneous Coronary Intervention (PCI). However, there exists inter-individual variability in drug response to the antiplatelet agents leading to recurrent thrombotic events. We sought to study the efficacy and variability of thienopyridines (clopidogrel and prasugrel), ticagrelor and triple antiplatelet therapy in Post-PCI percutaneous coronary intervention (PCI) patients using AggreGuide A-100 platelet aggregometer, a point-of-care-test (POCT) device using laser light scattering technique.
\end{abstract}

Methods: It was a single-centred prospective trial, included 405 patients who underwent PCI. Platelet reactivity was assessed by grading of platelet activity index (PAI) and considered as high on treatment platelet reactivity (HTPR) if PAI $>5$.

Results: Patients on clopidogrel showed significantly lower platelet inhibition compared to other groups ( $<<0.001)$. Females, elderly patients, non-smokers and patients who presented with acute coronary syndrome had significant HTPR $(\mathrm{p}<0.05)$. Compared to patients without HTPR, the occurrence of primary endpoints was not increased significantly in patients with HTPR. However in patients on clopidogrel, stent thrombosis was significantly high in patients with HTPR. TAPT had no significant stent thrombosis compared to DAPT regime containing clopidogrel and major bleeding complications were higher in patients treated with prasugrel and ticagrelor.

Conclusion: There was significant variability in response to antiplatelet therapy and integrating point of care tests in clinical practice may assist in individualising antiplatelet therapy, thus, reducing the rate of major cardiac events and without increasing the risk of bleeding. Keywords: Clopidogrel; Prasugrel; PCI; Ticagrelor

Abbreviations: PCI: Percutaneous Coronary Intervention; ACS: Acute Coronary Syndrome; BMS: Bare Metal Stent; DES: Drug Eluting Stent; DAPT: Dual Antiplatelet Therapy; TAPT: Triple Antiplatelet Therapy; POCT: Point-of Care Test; GCP: Good Clinical Practice; CAD: Coronary Artery Disease; WB: White Blood; SIHD: Stable Ischemic Heart Disease; PAI: Plasminogen Activator Inhibitor; ADP: Adenosine Diphophate; SPSS: Statistical Package for the Social Sciences; HTPR: High on Treatment Platelet Reactivity; CAMP: Cyclic AMP; EPO: Erythropoietin

\section{Introduction}

India is going through an epidemiologic vicissitude, marking a steep increase in the burden of non-communicable diseases. Coronary artery disease is the most common non-infectious disease and has risen from $17 \%$ of total deaths and $26 \%$ of adult deaths in 2001-2003 to $23 \%$ of total and $32 \%$ of adult deaths in 2010-2013, as reported by Registrar General of India [1].

In the contemporary clinical practice, percutaneous coronary intervention (PCI) is considered to be the most effective method of intervention for the treatment of acute coronary syndrome (ACS).

Over the years, there has been continuous evolution in the PCI technique, from plain old balloon angioplasty to bare metal stents (BMS) to drug-eluting stents (DES). DES, a milestone invention was initially acclaimed but is currently often denigrated owing to incomplete endothelization and stent thrombosis caused by these devices [2]. Animal studies have also reported complete endothelization with BMS at 28 days as contrast to DES, which shows dose-dependent delay in healing and endothelization, accounting for as long as 180 days [3]. Taking into consideration this limitation of DES, dual anti-platelet therapy (DAPT) with 
aspirin and clopidogrel for at least 6 months, followed by life-long aspirin therapy is recommended.

DAPT and newer, more potent antiplatelet P2Y12 receptor antagonist drugs, like prasugrel and ticagrelor, have improved clinical outcomes and reduced mortality after PCI. But still, a significant proportion of PCI population continues to experience recurrent ischemic events which may be attributed to non-responsiveness to this treatment. Besides medication non-compliance (pseudo resistance), pharmacodynamic and pharmacokinetic mechanisms are involved in variability in responsiveness to antiplatelet agents, and these include drug bioavailability, drug to drug interactions, cytochrome P-450 (CYP 450 ) activity and various genetic polymorphisms.

Thus, we sought to study the efficacy of thienopyridines, ticagrelor and triple antiplatelet therapy (TAPT) in post PCI patients using AggreGuide A-100 platelet aggregometer, a pointof-care-test (POCT) device using laser light scattering technique.

\section{Methods}

This was a single-centered, prospective study conducted at the tertiary care center in India. A written informed consent was obtained from all the patients enrolled in the study. The study was conducted according to the principles of Good Clinical Practice (GCP) and the Declaration of Helsinki between March 2015 and March 2017 and a total of 405 patients with coronary artery disease (CAD) were included in the study.

Patients were treated with DAPT with loading doses of both aspirin and either clopidogrel or prasugrel or ticagrelor followed by maintenance dose of these drugs. Few patients who were on clopidogrel were given additional cilostazol i.e., triple antiplatelet therapy. This was in accordance with treating physician's discretion and eligibility criteria.

Two millilitres (ml) of citrated whole blood (WB) sample for platelet aggregation testing was obtained on day 2 after maintenance dose of DAPT following PCI. If the patients were on GPIIb/IIIa inhibitors, sample was collected 2 days after tirofiban infusion and after 2 weeks in case of abciximab.

\section{Study population}

All the patients with CAD including both ACS and stable ischemic heart disease (SIHD) of either sex, age more than 18 years and had undergone PCI (primary PCI and elective PCI) were included. Patients using drugs affecting the metabolism of clopidogrel (phenytoin, proguanil, diazepam and some antidepressants), with renal failure, cirrhosis or with any chronic inflammatory disease, allergic to thienopyridines, with platelet count less than 1lakh/cu.mm or more than 5lakh/cu.mm., with anemia (hematocrit less than $30 \%$ ) or with polycythemia (hematocrit more than 52\%), with active bleeding (excluding menstruation) or significant gastrointestinal bleeding within the previous 6 months, those with history of hemorrhagic stroke or subarachnoid hemorrhage, who underwent major surgical procedure within 2 weeks before enrollment, patients who were unwilling to participate in the study and pregnant women were excluded from the study.

\section{Platelet aggregometer}

Assessment of platelet aggregation was done, using AggreGuide A-100 aggregometer. It is a POCT device based on the principle of light scattering technique. With this, more active the platelets, the more aggregates are formed and higher the PAI (Platelet Activity Index) (PAI $>5$ ). Conversely, if the platelets are inhibited by antiplatelet drugs, they are not activated by adenosine diphophate (ADP) to form aggregates and the AggreGuide shows a low PAI (PAI $\leq 5$ ), thus AggreGuide's PAI is a function of the number of aggregates.

\section{Data collection and follow-up}

A detailed demographic, historical, clinical, biochemical and hematological data were collected. In-hospital and 6 month clinical events were collected for all patients and recorded. The primary endpoints of the study were stent thrombosis, myocardial infarction and death. Secondary endpoints included in hospital major bleeding and other bleeding manifestations during the maintenance phase. These end points were studied in both the groups (low PAI and high PAI).

\section{Statistical analysis}

All the statistical analysis was performed with SPSS version 20.0 (IBM Corp., Armonk, NY: USA). Continuous data was presented as mean and standard deviation, while categorical variables were presented as counts with percentages. Differences observed, if any, were tested for significance with independent student's t-test for continuous data and Fischer's exact test or Chi-square test as appropriate for categorical data. Correlation between PAI and other variables was assessed with Pearson's correlation test. Relationship/Association between PAI and other parameters was assessed with Regression analysis. A p-value $<0.05$ was considered as significant.

\section{Results}

The demographic and baseline characteristics are shown in Table 1. The mean age of the study population was $55.7 \pm 9.9$ years.

Platelet aggregation inhibition testing was done which recorded that mean PAI was significantly high in females as compared to males $(4.1 \pm 2.4$ vs. $2.5 \pm 2.4, \mathrm{p}<0.001)$. The mean PAI in patients on clopidogrel (including/ excluding additional cilostazol), prasugrel and ticagrelor were $3.5 \pm 2.6,2.4 \pm 2.0$ and $1.8 \pm 1.8$ respectively and were showing statistically significant difference $(\mathrm{p}<0.001)$. Mean PAI in patients on only clopidogrel (without cilostazol) was $5.4 \pm 2.8$ while it was $3.0 \pm 2.3$ in patients on TAPT $(\mathrm{p}<0.001)$ (Table 2$)$.

Patients were classified as those having PAI $>5$ as High-on treatment platelet reactivity (HTPR) and PAI $\leq 5$. The mean age, mean BMI and mean of various haematological and biochemical parameters in patients with PAI $\leq 5$ and PAI $>5$ in four groups i.e., patients on clopidogrel, prasugrel, ticagrelor and on TAPT are 
shown in Table 3. Patients with PAI $>5$ had significantly higher age $(59.0 \pm 9.1$ vs. $55.1 \pm 9.9, \mathrm{p}<0.05)$ as compared to patients with PAI $\leq 5$. This significant difference was maintained in patients on clopidogrel and prasugrel, but was not seen in patients on ticagrelor.

Table 1: Baseline demographic characteristics.

\begin{tabular}{|c|c|}
\hline Baseline Characteristics & Number (\%) \\
\hline Age (years) & $55.7 \pm 9.9(\mathrm{SD})$ \\
\hline Female & $108(26.7 \%)$ \\
\hline Male & $297(73.3 \%)$ \\
\hline Hypertension & 193(47.7\%) \\
\hline Diabetes Mellitus & $151(37.3 \%)$ \\
\hline Dyslipidemia & $103(25.4 \%)$ \\
\hline Smoking & $158(39.0 \%)$ \\
\hline Previous ACS & $15(3.7 \%)$ \\
\hline Previous PCI & $15(3.7 \%)$ \\
\hline History of SIHD & $2(0.5 \%)$ \\
\hline History of CAD with insignificant disease & $2(0.5 \%)$ \\
\hline Post CABG & $1(0.3 \%)$ \\
\hline Beta Blockers & $364(89.9 \%)$ \\
\hline ACEIs/ ARBs & $276(68.2 \%)$ \\
\hline Diuretics & $224(55.3 \%)$ \\
\hline Statins & 402(99.3\%) \\
\hline H2 Receptor Blockers & 396(97.8\%) \\
\hline Proton Pump Inhibitors & $9(2.2 \%)$ \\
\hline
\end{tabular}

ACS: Acute Coronary Syndrome; PCl: Percutaneous Coronary Intervention; SIHD: Stable Ischemic Heart Disease; CAD: Coronary
Artery Disease; CABG: Coronary Artery Bypass Grafting; ACEI: Angiotensin Converting Enzyme Inhibitors; ARB's: Angiotensin II Receptor Blockers; SD: Standard Deviation

Table 2: Drug distribution and mean PAI values in study population.

\begin{tabular}{|c|c|c|c|c|}
\hline Drug & $\begin{array}{c}\text { Number of } \\
\text { Patients }\end{array}$ & $\begin{array}{c}\text { Number of } \\
\text { Patients } \\
\text { with PAI }>\mathbf{5}\end{array}$ & $\begin{array}{c}\text { Mean } \\
\text { PAI } \pm \text { SD }\end{array}$ & p value \\
\cline { 1 - 3 } $\begin{array}{c}\text { Clopidogrel } \pm \\
\text { Cilostazol }\end{array}$ & $221(54.6 \%)$ & $51(79.7 \%)$ & $3.5 \pm 2.6$ & \\
\cline { 1 - 3 } $\begin{array}{c}\text { Clopidogrel } \\
\text { (excluding patients } \\
\text { on TAPT) }\end{array}$ & $47(11.6 \%)$ & $23(36.0 \%)$ & $5.4 \pm 2.8$ & \multirow{2}{*}{$<0.001$} \\
\cline { 1 - 3 } $\begin{array}{c}\text { Clopidogrel + } \\
\text { Cilostazol (TAPT) }\end{array}$ & $174(43.0 \%)$ & $28(43.8 \%)$ & $3.0 \pm 2.3$ & \\
\cline { 1 - 3 } Prasugrel & $111(27.4 \%)$ & $8(12.5 \%)$ & $2.4 \pm 2.0$ & \\
\cline { 1 - 3 } Ticagrelor & $73(18.0 \%)$ & $5(7.8 \%)$ & $1.8 \pm 1.8$ & \\
\hline
\end{tabular}

TAPT: Triple Antiplatelet Therapy; PAI: Platelet Activity Index

In the clopidogrel group, it was seen that there was significant difference in haemoglobin and platelet count in patients with PAI $\leq 5$ than in those with PAI $>5$. Haemoglobin had a negative correlation, with strength of correlation being $28 \%$, while platelet count had a positive correlation with strength of correlation being $22 \%$. ( $p<0.001$ and 0.001 respectively). Regression analysis showed that $29.4 \%$ of change in platelet reactivity was due to haemoglobin and platelet count.

In the prasugrel group it was seen that there was statistically significant difference in age $(\mathrm{p}<0.001)$ and haemoglobin $(\mathrm{p}<0.001)$ within the groups with $\mathrm{PAI} \leq 5$ and $\mathrm{PAI}>5$. Correlation analysis showed significant $\mathrm{p}$ value with respect to age and haemoglobin and regression analysis showed that $41.8 \%$ of change in platelet reactivity was due to age and haemoglobin ( $\mathrm{p}=0.014$ and $\mathrm{p}<0.001$ respectively).

Table 3: Effect of demographic and Haematologic factors on PAI in clopidogrel and TAPT patients.

\begin{tabular}{|c|c|c|c|c|c|c|c|c|c|c|c|c|}
\hline \multirow[t]{2}{*}{ Variable } & \multicolumn{3}{|c|}{ Clopidogrel } & \multicolumn{3}{|c|}{ TAPT } & \multicolumn{3}{|c|}{ Prasugrel } & \multicolumn{3}{|c|}{ Ticagrelor } \\
\hline & $\mathrm{PAI}<5$ & $\mathrm{PAI}>5$ & $p$ value & $\mathrm{PAI}<5$ & PAI $>5$ & $p$ value & $\mathrm{PAI}<5$ & $\mathrm{PAI}>5$ & $p$ value & $\mathrm{PAI}<5$ & PAI $>5$ & p value \\
\hline $\begin{array}{c}\text { Age } \\
\text { (years) }\end{array}$ & $56 . \pm 9.9$ & $58 . \pm 8.7$ & 0.003 & $59.1 \pm 9.6$ & $56.2 \pm 9.6$ & 0.902 & $50 . \pm 8.4$ & 63.8 & 0.000 & $59.4 \pm 9.6$ & $54 . \pm 10.9$ & 0.255 \\
\hline $\begin{array}{c}\text { BMI } \\
(\mathrm{kg} / \mathrm{m} 2)\end{array}$ & $22 . \pm 3.9$ & $22 . \pm 4.5$ & 0.672 & $23.5 \pm 4.2$ & $22.5 \pm 4.0$ & 0.000 & $25 . \pm 2.9$ & $26 . \pm 3.5$ & 0.169 & $\begin{array}{c}23.8 \pm \\
4.3\end{array}$ & $29.7 \pm 0.0$ & 0.183 \\
\hline $\begin{array}{l}\text { Haemoglobin } \\
\text { (gm/dl) }\end{array}$ & $13 . \pm 2.1$ & $12 . \pm 1.8$ & 0.000 & $12.5 \pm 1.5$ & $13.4 \pm 2.2$ & 0.006 & $13 . \pm 1.7$ & $10 . \pm 2.2$ & $<0.001$ & $13.1 \pm 2.3$ & $12.9 \pm 2.8$ & 0.852 \\
\hline $\begin{array}{l}\text { Platelet count } \\
\text { (lakhs/mm3) }\end{array}$ & $2.6 \pm 0.8$ & $3.0 \pm 0.8$ & 0.002 & $2.8 \pm 1.0$ & $2.7 \pm 0.8$ & 0.695 & $2.5 \pm 0.6$ & $2.5 \pm 0.9$ & 0.885 & $2.5 \pm 0.7$ & $2.6 \pm 1.0$ & 0.701 \\
\hline $\begin{array}{c}\text { Total } \\
\text { cholesterol } \\
(\mathrm{mg} / \mathrm{dl})\end{array}$ & $\begin{array}{l}180.6 \\
\pm 49.8\end{array}$ & $\begin{array}{l}177.4 \\
\pm 42.9\end{array}$ & 0.709 & $\begin{array}{l}169.4 \\
\pm 37.5\end{array}$ & $\begin{array}{l}182.87 \\
\pm 50.6\end{array}$ & 0.068 & $\begin{array}{l}185.2 \\
\pm 40.9\end{array}$ & $\begin{array}{l}146.4 \\
\pm 47.2\end{array}$ & 0.051 & $\begin{array}{l}167.6 \\
\pm 56.5\end{array}$ & $\begin{array}{l}176.7 \\
\pm 38.6\end{array}$ & 0.786 \\
\hline HDL (mg/dl) & $35.5 \pm 6.7$ & $\begin{array}{l}35.8 \\
\pm 6.2\end{array}$ & 0.808 & $35 . \pm 4.8$ & $35.6 \pm 6.9$ & 0.062 & $35.5 \pm 5.3$ & $\begin{array}{l}34.8 \\
\pm 4.8\end{array}$ & 0.785 & $34.3 \pm 5.2$ & $36.0 \pm 6.0$ & 0.586 \\
\hline LDL (mg/dl) & $\begin{array}{l}113.3 \\
\pm 41.0\end{array}$ & $\begin{array}{l}113.1 \\
\pm 37.3\end{array}$ & 0.974 & $\begin{array}{l}104.6 \\
\pm 33.2\end{array}$ & $\begin{array}{l}115.7 \\
\pm 41.6\end{array}$ & 0.123 & $\begin{array}{l}118.0 \\
\pm 38.6\end{array}$ & $\begin{array}{c}87.0 \\
\pm 44.4\end{array}$ & 0.096 & $\begin{array}{l}105.9 \\
\pm 54.4\end{array}$ & $\begin{array}{l}115.3 \\
\pm 38.0\end{array}$ & 0.770 \\
\hline $\begin{array}{l}\text { Triglycerides } \\
\text { (mg/dl) }\end{array}$ & $\begin{array}{l}147.4 \\
\pm 96.8\end{array}$ & $\begin{array}{l}147.6 \\
\pm 53.2\end{array}$ & 0.858 & $\begin{array}{c}142.1 \\
\pm 64\end{array}$ & $\begin{array}{l}148.2 \\
\pm 94.7\end{array}$ & 0.387 & $\begin{array}{c}172.0 \\
\pm 113.4\end{array}$ & $\begin{array}{l}118.4 \\
\pm 52.9\end{array}$ & 0.303 & $\begin{array}{c}153.7 \pm 7 \\
4.1\end{array}$ & $\begin{array}{l}126.3 \\
\pm 27.6\end{array}$ & 0.530 \\
\hline
\end{tabular}


BMI: Body Mass Index; HDL: High Density Lipoprotein; LDL: Low Density Lipoprotein; PAI: Platelet Activity Index.

Patients on ticagrelor and on TAPT have not showed statistically significant difference in demographic and haematological factors in between the patients with PAI $<5$ and PAI $>5$. Smokers had low on-treatment platelet reactivity compared to non-smokers $3.1 \pm 2.3$ and $3.8 \pm 2.7$ respectively $(\mathrm{p}=0.041)$.

The outcomes in different antiplatelet drug groups are shown in Table $4 \& 5$. More number of stent thrombosis occurred in patients on clopidogrel $(p=0.01)$ while secondary endpoints (major bleeding) were more in prasugrel group ( $\mathrm{p}=0.019)$.

Table 4: Clinical endpoints in study population.

\begin{tabular}{|c|c|c|c|c|}
\hline Endpoints & $\begin{array}{c}\text { Clopidogrel } \\
\text { (221) }\end{array}$ & $\begin{array}{c}\text { Prasugrel } \\
\text { (111) }\end{array}$ & $\begin{array}{c}\text { Ticagrelor } \\
\text { (73) }\end{array}$ & p Value \\
\hline Death & $3(1.4 \%)$ & $4(3.6 \%)$ & $1(1.4 \%)$ & 0.35 \\
\hline $\begin{array}{c}\text { Stent } \\
\text { thrombosis }\end{array}$ & $5(2.3 \%)$ & $1(0.9 \%)$ & 0 & 0.32 \\
\hline $\begin{array}{c}\text { Myocardial } \\
\text { infarction }\end{array}$ & $2(0.9 \%)$ & 0 & 0 & 0.43 \\
\hline Bleeding & $5(2.3 \%)$ & $10(4.5 \%)$ & $5(6.8 \%)$ & 0.019 \\
\hline
\end{tabular}

Table 5: Incidence of stent thrombosis in clopidogrel patients.

\begin{tabular}{|c|c|c|c|}
\hline & PAI <5 & PAI $>\mathbf{5}$ & p Value \\
\hline Number of Patients & 170 & 51 & \\
\hline Number of Stent Thrombosis & $1(0.5 \%)$ & $4(7.8 \%)$ & 0.01 \\
\hline
\end{tabular}

\section{Discussion}

This study, which aimed to determine the efficacy of thienopyridines, ticagrelor and triple antiplatelet therapy (TAPT) in post PCI patients, demonstrated that platelet aggregation inhibition in response to antiplatelet drugs varies widely. In the present study, it was found that $15.8 \%$ of patients on antiplatelet therapy were having HTPR, of which majority were on clopidogrel $(79.7 \%, \mathrm{p}<0.001)$. The incidence of clopidogrel non-responsiveness was found to be $23.0 \%$, consistent with the prevalence of clopidogrel nonresponse of about $4-30 \%$ in previous studies [4-6]. A huge variation has been observed in the reported rates of clopidogrel non-responsiveness due to several different techniques used to evaluate platelet function.

The present study showed that compared to other drugs clopidogrel and prasugrel showed positive correlation with age in patients with $\mathrm{PAI}<5$ and $\mathrm{PAI}>5$ which was equivalent with the finding of SENIOR platelet trails [7] in which they found two fold elevated rate of HTPR in elderly patients ( $>75$ years) than younger $(p<0.001)$. On the contrary, Price et al. [8] assessed patients, who were on continuous clopidogrel therapy rather than with loading dose of clopidogrel prior to angioplasty, as in the present study and demonstrated that age has no impact on platelet reactivity. The reduction in response of clopidogrel and prasugrel in elderly patients could be due to the physiological reduction in liver function which leads to decrease formation of their active metabolites (as both are pro-drugs) and also due to more co-morbidity observed in elderly patients.

Females were found to have significantly higher PAI compared to males which was similar to previous findings [9]. The possible mechanism for this was high prevalence of ABCB1 polymorphisms in females, which causes efflux of clopidogrel leading to decrease in bioavailability and ultimately increase platelet reactivity [10].

In the present study, it was observed that smoking had negative correlation with PAI in patients on clopidogrel $(\mathrm{p}=0.02)$ i.e. smokers showed increased platelet inhibition by clopidogrel compared to non-smokers and this observation was homogeneous with the results of the study conducted by Bliden et al. [11]. As cigarette smoking can activate CYP1A2 isoenzyme in liver, it can lead to elevation in active metabolite of clopidogrel, thereby enhancing antiplatelet response.

Prasugrel and ticagrelor, both are P2Y12 receptor antagonists having several pharmacological advantages over clopidogrel. Prasugrel is also a prodrug like clopidogrel, effectively converts to its active metabolite and displays a faster onset of action with greater degree of platelet inhibition and less variability in response, even when compared with high dose clopidogrel [12]. Various previous studies like PRINCIPEL TIMI 44 [12] and TRITON TIMI 38 [13] have compared prasugrel and clopidogrel in loading as well as maintenance dose and found that prasugrel achieved a greater inhibition of platelet reactivity in consistent to the present study results.

On other hand, ticagrelor does not require metabolic activation and produces more rapid onset of action than clopidogrel. The study by Bliden et al. [14] reported that compared to clopidogrel, ticagrelor acts rapidly and is even associated with low (0-8\%) prevalence of HTPR as assessed with the Verify now assay and similarly, the present study also showed that patients on ticagrelor had significantly low PAI compared to clopidogrel $(\mathrm{p}<0.001)$.

Cilostazol, a phosphodiesterase III inhibitor, the enzyme involved in conversion of cyclic AMP (cAMP) to 5'AMP causing subsequent increase in cAMP within platelets, leading to inhibition of platelet aggregation. It has shown to increase platelet inhibition and also reduces stent restenosis and the extent of late loss when it has been added to aspirin and clopidogrel as a part of TAPT regimen $[15,16]$. In consistent to this, the present finding also represented that TAPT $(n=174)$ significantly reduced the PAI compared to patients on only clopidogrel $(n=47)(3.0 \pm 2.3$ vs. $5.4 \pm 2.8, \mathrm{p}<0.001$ ), respectively. In the previous retrospective study, it was demonstrated that TAPT significantly reduces stent thrombosis than in DAPT ( $\mathrm{p}=0.024)$ [17].

On comparing all the antiplatelet therapies, clopidogrel was found to be significantly inferior to all other drugs in reducing platelet reactivity whereas prasugrel and ticagrelor both were equally effective in reducing the platelet reactivity. However, 
prasugrel and ticagrelor were found to be equally effective and superior to TAPT, respectively.

Low haemoglobin and increased platelet count were significantly linked with increase in platelet reactivity in patients on clopidogrel, although patients with hemoglobin $<10 \mathrm{gm} \%$ were excluded and patients with normal platelet counts were only included in the study. However, such association was not observed in patients on ticagrelor. The probable mechanism involved in association of low hemoglobin and platelet activity may be due to increase in erythropoietin (EPO) level, which ultimately activate platelets [18].

The present study demonstrated more number of stent thrombosis and myocardial infarction (primary outcomes) in patients on clopidogrel $(n=5, n=2)$ compared to both prasugrel $(n=1, n=0)$ and ticagrelor $(n=0, n=0)$, but was not found statistically significant. However, the previous study by Gabriel et al. [19] stated that ticagrelor reduces the incidence of stent thrombosis compared to clopidogrel. Furthermore, incidence of stent thrombosis was significantly higher in patients on clopidogrel having PAI $>5$ compared to PAI $<5(p=0.01)$. On other hand, bleeding incidence was significantly higher in patients on prasugrel $(\mathrm{n}=10)$ as compared to clopidogrel $(\mathrm{n}=5)$ and ticagrelor $(\mathrm{n}=5)(\mathrm{p}=0.019)$, which was similar to the findings by Thomas et al. [20] in which they assessed the occurrence of bleeding complications by prasugrel. No significant difference in any of the primary outcomes between different antiplatelet drugs were observed in the present study, thus there is need to study these outcomes in more number of patients.

\section{Limitations}

The study was conducted on small sample size and was single-centered, hence significant difference in outcomes was not observed and the results cannot be generalized to total population. No standardized method for testing platelet function is available today, hence the results of our assay should have been compared with another platelet function test like Verify now using which previous studies had been performed to compare accuracy of results, but this would have been an expensive strategy.

\section{Conclusion}

Individualizing antiplatelet therapy using standardized methods of platelet function testing and interpreting variability of individual or combination of antiplatelet drugs may reduce rate of adverse outcomes with ACS and PCI. From the current finding, it can be stated that TAPT, prasugrel and ticagrelor showed more effective decrease in platelet reactivity than clopidogrel alone and they also reduce event of stent thrombosis compared to clopidogrel in post-PCI patients. From the present study, it is safe to convey that this strategy reduces the rate of major cardiac events and stent thrombosis for short term, without increasing the risk of bleeding but further studies on its sustained benefit for long term are pending.

\section{Author's Contribution}

a) Conception and design: RM, DR

b) Administrative support: RM, DR, VV, GR

c) Provision of study material or patients: RM, DR, VV, GR, CK

d) Collection and assembly of data: RM, DR, GS

e) Data analysis and interpretation: RM, DR, VV, GR, CK, GS

f) Manuscript writing: All authors

g) Final approval of manuscript: All authors

\section{References}

1. Gupta R, Mohan I, Narula J (2016) Trends in coronary heart disease epidemiology in India. Ann Glob Health 82(2): 307-315.

2. Kotani J, Awata M, Nanto S, Uematsu M, Oshima F, et al. (2006) Incomplete neointimal coverage of sirolimus-eluting stents: angioscopic findings. J Am Coll Cardiol 47(10): 2108-2111.

3. Tsimikas S (2006) Drug-eluting stents and late adverse clinical outcomes lessons learned, lessons awaited. J Am Coll Cardiol 47(10): 2112-2115.

4. Järemo P, Lindahl T, Fransson SG, Richter A (2002) Individual variations of platelet inhibition after loading doses of clopidogrel. J Intern Med 252(3): 233-238.

5. Gurbel PA, Bliden KP, Hiatt BL, O'Connor CM (2003) Clopidogrel for coronary stenting. Circulation 107(23): 2908-2913.

6. Muller I, Besta F, Schulz C, Massberg S, Schonig A, et al. (2003) Prevalence of clopidogrel non-responders among patients with stable angina pectoris scheduled for elective coronary stent placement. Thromb Haemost 89(5): 783-787.

7. Silvain J, Cayla G, Hulot JS, Finzi J, Kerneis M, et al. (2011) High onthienopyridine platelet reactivity in elderly coronary patients: the senior-platelet study. Eur Heart J 33(10): 1241-1249.

8. Price MJ, Nayak KR, Barker CM, Kandzari DE, Teirstein PS (2009) Predictors of heightened platelet reactivity despite dual-antiplatelet therapy in patients undergoing percutaneous coronary intervention. Am J Cardiol 103(10): 1339-1343.

9. Breet N, Sluman M, van Berkel M, Van Werkum J, Bouman H, et al. (2011) Effect of gender difference on platelet reactivity. Neth Heart J 19(11): 451-457.

10. Sridharan K, Kataria R, Tolani D, Bendkhale S, Gogtay NJ, et al. (2016) Evaluation of CYP2C19, P2Y12, and ABCB1 polymorphisms and phenotypic response to clopidogrel in healthy Indian adults. Indian J Pharmacol 48(4): 350-354.

11. Bliden KP, DiChiara J, Lawal L, Singla A, Antonino MJ, et al. (2008) The association of cigarette smoking with enhanced platelet inhibition by clopidogrel. J Am Coll Cardiol 52(7): 531-533.

12. Wiviott SD, Trenk D, Frelinger AL, O’Donoghue M, Neumann FJ, et al. (2007) Prasugrel compared with high loading-and maintenancedose clopidogrel in patients with planned percutaneous coronary intervention. Circulation 116(25): 2923-2932.

13. Wiviott SD, Braunwald E, McCabe CH, Montalescot G, Ruzyllo W, et al (2007) Prasugrel versus clopidogrel in patients with acute coronary syndromes. N Engl J Med 357(20): 2001-2015.

14. Bliden KP, Tantry US, Storey RF, Jeong YH, Gesheff M, et al. (2011) The effect of ticagrelor versus clopidogrel on high on-treatment platelet 
reactivity: combined analysis of the onset/offset and respond studies. Am Heart J 162(1): 160-165.

15. Angiolillo DJ, Capranzano P, Goto S, Aslam M, Desai B, et al. (2008) A randomized study assessing the impact of cilostazol on platelet function profiles in patients with diabetes mellitus and coronary artery disease on dual antiplatelet therapy: results of the optimus-2 study. Eur Heart J 29(18): 2202-2211.

16. Liu Y, Shakur Y, Yoshitake M, Kambayashi Ji (2001) Cilostazol (Pletal@): a dual inhibitor of cyclic nucleotide phosphodiesterase type 3 and adenosine uptake. Cardiovasc Drug Rev 19(4): 369-386.

17. Lee SW, Park SW, Hong MK, Kim YH, Lee BK, et al. (2005) Triple versus dual antiplatelet therapy after coronary stenting: impact on stent thrombosis. J Am Coll Cardiol 46(10): 1833-1837.
18. Toma C, Zahr F, Moguilanski D, Grate S, Semaan RW, et al. (2012) Impact of anemia on platelet response to clopidogrel in patients undergoing percutaneous coronary stenting. Am J Cardiol 109(8): 1148-1153.

19. Steg PG, Harrington RA, Emanuelsson H, Katus HA, Mahaffey KW, et al. (2013) Stent thrombosis with ticagrelor versus clopidogrel in patients with acute coronary syndromes: an analysis from the prospective randomized plato trial. Circulation 128(10): 1055-1065.

20. Cuisset T, Loosveld M, Morange PE, Quilici J, Moro PJ, et al. (2012) CYP2C19* 2 and* 17 alleles have a significant impact on platelet response and bleeding risk in patients treated with prasugrel after acute coronary syndrome. JACC Cardiovasc Interv 5(12): 1280-1287.

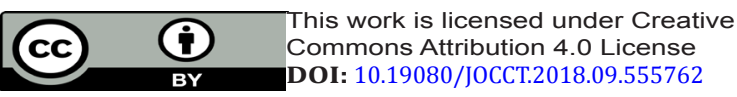

